\title{
Recovery of Crude Oil from Aqueous Medium by Optimised Styrene/Kenaf Shive Graft-Based Sorbent Via Regeneration Method: Study of the Equilibrium, Kinetics and Activation Energy
}

\author{
Salisu Z. M., Ishiaku S.U., Abdullahi D, Yakubu M.K., Diya Uddeen B.H.
}

\begin{abstract}
The area of research that cast the mind of many environmentalist is remediation of oil spilled environments. This paper addresses the development of new bio-based sorbent through ceric induced grafting. The effect studies of the individual and combine factors was carried out using a statistical experimental design matrix using five-level central composite design (CCD). Respond surface methodology (RSM) was used to optimise and develop equations of the variables (initiator concentration, monomer ratio and particle sizes). To the optimized sorbent, unmodified kenaf shive was compared with, it reveals a positive hydrophobic shift. However, instrumental analysis such as: XRD, FTIR, BET and DTA-TGA were carried out on the optimized sorbent. In addition, the capability of the oil sorption in water was reported and the kinetics and equilibrium isotherms employed fits respectively, the pseudo-second order and Langmuir isotherm with regression coefficient $R^{2}=0.9822$ and $R^{2}=0.9900$. The sorption property was found to be spontaneous and exothermic, however, the activation energy studies shows physic-sorption phenomenon with $25.6 \mathrm{kJmol}^{-1}$ and $R^{2}=0.9847$.
\end{abstract}

Index Terms - kenaf shive, design matrix, grafting, kinetic, isotherm, physic-sorption.

\section{INTRODUCTION}

Highlight Crude oil is one of the major sources of income bestowed under the earth's crust of most developed countries. But because of environmental issues associated with exploration, transportation and refining of the crude oil, this very important revenue earner becomes a menace for most of developing countries mainly due to spillage $[1,10,14,26]$.

Oil spills is considered as one of the most serious disasters that is threatening the marine ecosystem [18, 20-24]. Many techniques have been devised to combat this problem [3]. These techniques include: burning in situ, bioremediation, chemical dispersion and synthetic sorbents in spite of their secondary effect of non-degradability [3, 5-6, 23]. The most widely accepted by many researchers and industries is the one

Salisu Z. M., National Research Institute for Chemical Technology (NARICT), Basawa, Zaria, Nigeria

Ishiaku S.U., Department of Polymer and Textile Engineering, Ahmadu Bello University (ABU), Zaria, Nigeria

Abdullahi D, Department of Polymer and Textile Engineering, Ahmadu Bello University (ABU), Zaria, Nigeria

Yakubu M.K., Department of Polymer and Textile Engineering, Ahmadu Bello University (ABU), Zaria, Nigeria

Diya Uddeen B.H., Center for Energy Research and Training (CERT), Ahmadu Bello University (ABU), Zaria, Nigeria prepared from polyurethane and polypropylene fibres and is now being considered hazardous $[2,16,22]$. Owing to the cost implication associated to incineration of these synthetic and the preparation of nanocellulose sorbents lead to the revolution of natural sorbents.

The two preeminent properties which were lacking in natural (cellulosic) sorbents: hydrophobicity and oleophilicity are now improved via surface coating or/and regeneration [11, 17-24].

This paper addresses the oil spill clean-up using ceric induced grafting methods (regeneration) on kenaf shive that is sustainable, cost effective and eco-friendly. Kenaf plant is one of the fast growing plant which adapts to different climatic changes. The shive constitutes about $60-70 \%$ of the plant, however, have little or no economic importance and available at our door step. Styrene being hydrophobic was used to incorporate the hydrophobic properties that inturn enhanced the oleophilicity.

\section{MATERIALS AND MethodS}

All chemicals are analytical grades and used how it was received without further purification, except for the monomer (acrylonitrile) which inhibitors were removed by washing it severally with $5 \%$ concentration of $\mathrm{NaOH}$. However, stabilizers removal for Acrylic acid and Acrylamide was achieved by vacuum distillation and recrystallization with acetone, respectively. Dried Kenaf stalks were obtained from National Research Institute for Chemical Technology (NARICT), Zaria

\section{A. Source of Crude Oil}

The crude oil sample used for the sorption test was obtained from Petroleum Research Laboratory, Warri, Delta state, Nigeria. The raw crude oil was kept at room temperature. However, the adsorption test for modified and unmodified kenaf shive in preliminary runs was carried out at $40^{\circ} \mathrm{C}$. Table 1 shows the significant properties of the oil that perhaps affect the oil sorption.

\section{B. Experimental Procedures}

The obtained dried kenaf stalks were subjected to chemical retting, $1 \% \mathrm{w} / \mathrm{v} \mathrm{NaOH}$ for $2 \mathrm{hrs}$ in order to extract its shive from the two components (shive and bast fibres). The product was washed with distilled water until neutrality was achieved 


\section{Recovery of Crude Oil from Aqueous Medium by Optimised Styrene/Kenaf Shive Graft-Based Sorbent Via Regeneration Method: Study of the Equilibrium, Kinetics and Activation Energy}

and further drying took place for $72 \mathrm{hrs}$ at room temperature. The extracted shive was ground into different particle sizes as prescribed by the DoE software result sheet.

Synthesis of the grafted sorbent was done by soaking requisite quantity $(1.00 \mathrm{~g})$ of kenaf shive in $5 \mathrm{mls}$ of distilled water for $24 \mathrm{hrs}$. The mixture was transferred to reaction kettle and $1.00 \mathrm{ml}$ of $2 \%$ acetic acid, $10.00 \mathrm{ml}$ of $0.4 \mathrm{M}$ of nitric acid and $0.5 \mathrm{ml}$ of the weight percent of the requisite quantities of initiator as well as monomer concentration as in the aforementioned Tables; were added, however, the monomer was added after purging nitrogen gas for $5 \mathrm{~min}$. The reaction continued for $3 \mathrm{hrs}$ at $60^{\circ} \mathrm{C}$. The sample was then washed, filtered and oven dried at $40^{\circ} \mathrm{C}$.

Three neck flask was quarterly filled with about $25 \mathrm{ml}$ of acetone for homopolymers removal. The initial weight of the thimble was taken after which the thimble plus grafted shive was noted. The latter was inserted into the extractor for the extraction process. This was done at $60^{\circ} \mathrm{C}$ for $24 \mathrm{hrs}$ in which the homopolymers weight were calculated as in Table 3 . The experimental processes were repeated for twenty samples using requisites regressors as in Table 1.

The extracted grafted sorbents were tested for crude oil sorption using requisite quantity of the sorbent $(0.10 \mathrm{~g})$ into watch glass containing $5 \mathrm{mls}$ of the oil. This was done at $40^{\circ} \mathrm{C}$ for 5 mins to achieve proper sorption.

Adsorption capabilities of both optimized extracted and unextracted homopolymer sorbents were compared.

\section{Characterisations}

Infrared spectra of the sorbent in $\mathrm{KBr}$ pellets is analysed and scanned from $4000-400 \mathrm{~cm}^{-1}$ using Shimadzu FTIR-8400S. This test was carried out on the optimized unextracted sorbent -that has the highest oil sorption- to confirm the modifications by taking the advantage of their analyzed functional groups. The sorbent crystallinity was determine using Shimadzu XRD 6000 (Tokyo, Japan) with CuKaradiation ( $\lambda=1.542 \AA$ ) operated at $30 \mathrm{kV}$ and $30 \mathrm{~mA}$. Surface area was determined using Brunauer, Emimett and Teller(BET) technique by (Quantachrome Instruments, Model Nova1000e series, USA), however, the heat properties was not set aside but determine using DTA-TGA60 Shimadzu, Japan.

\section{Adsorbability Measurement}

Oil adsorption capability for both preliminaries and the optimized extacted as well as unextracted sorbent of the modified kenaf shive fibers was investigated. According to ASTM F-726-12, the adsorption capacity formula is expressed as follows $[7,15]$ :

$$
S_{w}=\frac{s_{w t}-s_{0}}{s_{0}}
$$

where $\mathrm{Sw}$ is the sorption rate (g (liquid)/g (sorbent)), So is the quality of the shive fibre before sorption, and Swt is the quality of the kenaf shive fiber after sorption. We took $1 \mathrm{~g}$ of raw and modified shive fibres, immersed them in a beaker, and took measurements every $5 \mathrm{~min}$. According to ASTMF-726-12, the test measures the rapid adsorption capacity (15 min soaking) and $24 \mathrm{~h}$ adsorption capacity. The sea water used for this test is a natural seawater not simulated.

\section{E. Batch Experiments}

Equal mixture of $15 \mathrm{~mL}$ petroleum ether and $1 \mathrm{~mL}$ of $1+1$ sulfuric acid were shaken in a reparatory funnel for $15 \mathrm{mins}$ The lower aqueous organic layer was released after settling for about $10 \mathrm{~min}$. The organic layer was poured into a beaker containing $1.2 \mathrm{~g}$ of drying agent (anhydrous sodium sulfate), then the mixture was drain into glass funnel. Consequently, the solution was filtered into the colorimeter coupled with $25 \mathrm{~mL}$ of petroleum ether (this was repeated with the same quantity of petroleum ether). The residual oil concentration was determined by filtering the sorbent and analysed using $\mathrm{UV}-\mathrm{V}$ is spectroscopy.

Adsorption kinetics were performed by immersing $1 \mathrm{~g}$ of developed sorbent a mixture of oil/sea water at room temperature. Samples and crude oil concentration were, respectively, weighed and measured at different time interval, between 1-90min.

Isotherm studies was carried out at room temperature (298K) by varying the initial concentrations $5-30 \mathrm{~g} / \mathrm{L}$ at interval of $5 \mathrm{~g} / \mathrm{L}$ using the aforementioned procedure.

The adsorption thermodynamics and activation energies (Ea) were determined via the batch experiments at different temperatures (298, 303, 313 and 323K).

The crude adsorption capacity at equilibrium (Q) is calculated by the following formula:

$$
Q=\frac{\left(C_{Q}-C_{q}\right) V}{s}
$$

Where, $\mathrm{Co}$ and $\mathrm{Ce}$ are, respectively, the initial and equilibrium concentrations of crude oil $(\mathrm{g} / \mathrm{L})$ at any time $\mathrm{t}$. V is the volume of the solution $(\mathrm{L})$, and $\mathrm{S}$ is the mass of the adsorbent (g).

2.6 Adsorption kinetics

2.6.1 Pseudo first-order model

The pseudo-first-order model is represented by the following equation $[7,11]$ :

$$
\frac{d Q_{t}}{d t}=K_{1}\left(Q_{\theta}-Q_{t}\right)
$$

When boundary conditions are reached, $\mathrm{t}=0, \mathrm{Q}=0$ and $\mathrm{t}=$ $\mathrm{t}, \mathrm{Q}=\mathrm{Qt}$, the equation can change to:

$$
\ln \left(Q_{e}-Q_{t}\right)=\ln Q_{e}-K_{1} t
$$

this is simplified as:

$Q_{t}=Q_{e}\left(1-e^{-K_{1} t}\right)$

Where, $\mathrm{k}_{1}$ is the pseudo first-order rate constant; Qe and Qt are the adsorption capacities of the adsorbent at equilibrium.

2.6.2 Pseudo second-order model

The pseudo second-order model is represented as follows $[17,19]$ :

$$
\frac{d Q t}{d t}=k_{2}\left(Q_{e}-Q_{t}\right)^{2}
$$

The linearized-integrated form of the equation is:

$$
Q_{\mathrm{t}}=\frac{k_{2} Q_{\mathrm{s}}{ }^{2} \mathrm{t}}{1+k_{2} Q_{\mathrm{z}} t}
$$

where $\mathrm{k} 2$ is the pseudo second-order rate constant.

2.6.3 Intraparticle diffusion model

The intraparticle diffusion model can be used to analyze the removal of pollutants by an absorbent during a diffusion 
process. This is expressed as the following equation [7, 20]:

$$
Q_{t}=k_{p} t^{0.5}+C
$$

where $\mathrm{kp}$ is the intraparticle diffusion rate constant; and $\mathrm{C}$ is a constant related to the bounding layer thickness.

\section{F. Adsorption Isotherm}

\section{Langmuir isotherm model}

The Langmuir isotherm model assumes that adsorption occurs at a specific uniform location on the adsorbent surface. According to this model, the adsorbent forms a molecular monolayer.

The equation is as follows $[7,12,16]$ :

$$
Q_{e}=\frac{k_{1} Q_{0} C_{2}}{1+k_{1} C_{2}}
$$

where Qo is the maximum adsorption capacity of the adsorbent $(\mathrm{g} / \mathrm{g})$; and $\mathrm{K} 1$ is the Langmuir constant of equilibrium adsorption.

\subsubsection{Freundlich isotherm model}

The Freundlich isotherm model assumes that multilayer adsorption takes place at heterogeneous surfaces with different adsorption energies and characteristics. Here, the adsorption of the surface is calculated by the following equation [16]:

$$
Q_{\theta}=k_{2} C_{e}^{1 / n}
$$

where $\mathrm{K} 2(\mathrm{mg} / \mathrm{g})(\mathrm{L} / \mathrm{mg}) 1 / \mathrm{n}$ is the Freundlich constant; and $\mathrm{n}$ is the adsorption intensity.

\section{G. Adsorption Thermodynamics}

The adsorption thermodynamics of the diesel adsorption process need to be further investigated. Various thermodynamic parameters such as enthalpy $(\Delta \mathrm{H})$, entropy $(\Delta \mathrm{S})$, and Gibbs free energy $(\Delta \mathrm{G})$ can be obtained by isothermal adsorption studies [7- 9, 25]. $\Delta \mathrm{G}$ of adsorption can be represented by the classical van't Hoff equation:

$$
\Delta \mathrm{G}=R T \ln K o
$$

\begin{tabular}{|c|c|c|c|c|c|c|}
\hline Sample & $\begin{array}{c}\mathbf{K} . \\
\left(\mathbf{m}^{2} / \mathbf{s}\right)\end{array}$ & Viscosity & $\begin{array}{l}\text { Speed } \\
\left(\mathrm{m} / \mathbf{s}^{2}\right)\end{array}$ & $\begin{array}{l}\text { Torgue } \\
(\mathrm{Nm})\end{array}$ & $\begin{array}{l}\text { Temp. } \\
\left({ }^{0} \mathrm{C}\right)\end{array}$ & $\begin{array}{l}\text { Density } \\
\left(\mathrm{g} / \mathrm{cm}^{3}\right)\end{array}$ \\
\hline \multirow[t]{2}{*}{ Crude oil } & 1.33 & & 30.00 & 0.10 & 24.5 & 0.8965 \\
\hline & 0.67 & & 60.00 & 0.00 & 24.5 & \\
\hline
\end{tabular}

where $\mathrm{K}_{0}$ can be calculated by the following equation:

$$
K_{0}=\text { Qe } / \mathrm{Ce}
$$

Table 1- Specifications of crude oil samples

In Table 1, the physical properties of the used crude oil was expatiated. Hence, viscosity and density played a vital role in

\begin{tabular}{|c|c|c|c|c|c|c|c|c|c|}
\hline \multicolumn{10}{|c|}{ Results } \\
\hline \multirow{2}{*}{$\begin{array}{l}\text { Run } \\
\text { no }\end{array}$} & \multicolumn{5}{|c|}{ Experimental design } & \multicolumn{2}{|c|}{ Experimental } & \multicolumn{2}{|c|}{ Predicted } \\
\hline & $\begin{array}{l}\text { Monomer } \\
\text { ratio } \\
(\%)-\mathrm{A}\end{array}$ & $\begin{array}{l}\text { Particle } \\
\text { size } \\
(\mu \mathrm{m})-B\end{array}$ & $\begin{array}{l}\text { Initiator } \\
\text { conc. } \\
(\%)-C\end{array}$ & $\begin{array}{l}\text { Density } \\
\left(\mathrm{g} / \mathrm{cm}^{3}\right)\end{array}$ & $\begin{array}{l}\text { Homopolymer } \\
\text { (g) }\end{array}$ & $\begin{array}{l}\text { Grafting } \\
\text { efficiency }\end{array}$ & $\begin{array}{c}\% \\
\text { swelling }\end{array}$ & $\begin{array}{l}\text { Grafting } \\
\text { efficiency }\end{array}$ & $\begin{array}{c}\% \\
\text { swelling }\end{array}$ \\
\hline 1 & 5.00 & 125.00 & 0.50 & 0.075 & 0.021 & 10.48 & 176.20 & 6.012156 & 78.7694 \\
\hline 2 & 5.00 & 125.00 & 2.50 & 0.068 & 0.049 & 17.67 & 472.08 & 17.57742 & 467.8264 \\
\hline 3 & 12.50 & 1000.00 & 1.50 & 0.088 & 0.036 & 30.91 & 457.80 & 30.16935 & 483.3463 \\
\hline 4 & 20.00 & 562.50 & 0.50 & 0.106 & 0.027 & 7.33 & 419.08 & 7.928607 & 253.4254 \\
\hline 5 & 5.00 & 562.50 & 0.50 & 0.140 & 0.004 & 3.99 & 101.60 & 4.080156 & 135.5976 \\
\hline 6 & 20.50 & 1000 & 2.50 & 0.120 & 0.026 & 12.47 & 224.60 & 16.19304 & 284.4126 \\
\hline
\end{tabular}
adsorption. However, different crude oil physical properties were recorded and is one of yardstick used in it distinguishing. This is in side of the heavy crude oil. This has some difficulties in penetrating through the sorbent than the medium or light crudes [21].

Table 2- Design matrix for crude oil styrene (ST) modified sorbents
The apparent enthalpy $(\Delta \mathrm{H})$ of adsorption and the entropy $(\Delta \mathrm{S})$ are calculated as follows:

$$
\ln \left(\frac{Q_{g}}{C_{q}}\right)=\frac{\Delta S}{T}-\frac{\Delta H}{R T}
$$
$(\mathrm{kJ} /(\mathrm{molK})) ; \mathrm{R}$ is the universal gas constant $(8.314 \mathrm{~J} / \mathrm{mol}) ; \mathrm{T}$

\section{Activation energy}

The activation energy can be determined from the change of the absorption rate constant, $\mathrm{k}$ with temperature, $\mathrm{T}(\mathrm{K})$

$$
\ln k=\ln A-\frac{E_{\mathrm{a}}}{R T}
$$

Where $\mathrm{A}$ is the pre-exponential factor obtained from the intercept plot of lnk versus1/T and $\mathrm{R}$ is the gas constant $(8.314 \mathrm{~J} / \mathrm{mol} \mathrm{K})$. By plotting $\ln [\mathrm{k}]$ against $1 / \mathrm{T}$, Ea can be calculated from the slope. Plots of kinetic rate constants of the best fitted model versus $1 / \mathrm{T}$ were obtained.

\section{Characterisation}

[1] Infrared spectra of the sorbent in $\mathrm{KBr}$ pellets is analysed and scanned from $4000-400 \mathrm{~cm}^{-1}$ using Shimadzu FTIR-8400S. This analysis was carried out on the raw kenaf shive (unmodified) and the optimized developed sorbent. Further characterization were conducted on the developed sorbents; X-ray diffraction analysis using a Shimadzu XRD 6000 X-ray diffractometer (Tokyo, Japan), DTA-TGA and BET.

\section{RESULTS AND DiSCUSSIONS}

\section{A. The crude oil sample was characterised using} Rheometer instrument. is the adsorption temperature $(\mathrm{K})$. 
Recovery of Crude Oil from Aqueous Medium by Optimised Styrene/Kenaf Shive Graft-Based Sorbent Via Regeneration Method: Study of the Equilibrium, Kinetics and Activation Energy

\begin{tabular}{|l|l|c|l|l|l|l|l|l|l|}
\hline 7 & 5.00 & 562.50 & 2.50 & 0.058 & 0.054 & 4.95 & 98.96 & 1.972666 & 76.74213 \\
\hline 8 & 12.50 & 562.50 & 1.50 & 0.072 & 0.045 & 31.88 & 479.70 & 23.50816 & 400.0642 \\
\hline 9 & 12.50 & 562.5 & 0.50 & 0.078 & 0.012 & 5.43 & 110.98 & 8.229856 & 193.4136 \\
\hline 10 & 12.50 & 1000.00 & 1.50 & 0.071 & 0.058 & 32.46 & 567.90 & 30.16935 & 483.3463 \\
\hline 11 & 12.50 & 125.00 & 2.50 & 0.102 & 0.010 & 23.06 & 414.20 & 23.2454 & 422.7043 \\
\hline 12 & 20.00 & 125.00 & 2.50 & 0.074 & 0.001 & 25.30 & 421.64 & 24.46244 & 379.7779 \\
\hline 13 & 12.50 & 1000.00 & 1.50 & 0.085 & 0.019 & 29.92 & 479.57 & 30.16935 & 483.3463 \\
\hline 14 & 12.50 & 125.00 & 1.50 & 0.083 & 0.042 & 24.56 & 286.69 & 29.77302 & 421.7279 \\
\hline 15 & 12.50 & 1000.00 & 1.50 & 0.079 & 0.034 & 31.11 & 487.96 & 30.16935 & 483.3463 \\
\hline 16 & 20.00 & 562.50 & 1.50 & 0.074 & 0.022 & 29.68 & 480.30 & 25.21781 & 481.3391 \\
\hline 17 & 12.50 & 562.50 & 1.50 & 0.083 & 0.042 & 30.85 & 482.65 & 23.50816 & 400.0642 \\
\hline 18 & 20.00 & 562.50 & 0.50 & 0.075 & 0.032 & 6.95 & 106.78 & 7.928607 & 253.4254 \\
\hline 19 & 12.50 & 562.50 & 1.50 & 0.083 & 0.042 & 12.27 & 404.01 & 23.50816 & 400.0642 \\
\hline 20 & 5.00 & 562.50 & 1.50 & 0.073 & 0.044 & 9.90 & 231.09 & 17.34756 & 320.9851 \\
\hline
\end{tabular}

\section{B. Structural Characterisation}

In Figure 1 is the FTIR spectra indicating peaks of the raw (unmodified) and, modified (optimized sorbent) kenaf shive. The results are fully discussed in [14] for succinctness is not discussed herein. The Brunure-Emmitte-Teller (BET) result is briefly discussed here. The BET results indicates an increase in surface area from 100 to $301.1 \mathrm{~m}^{2} / \mathrm{g}$. This attributes to the high crude oil sorption of the optimized sorbent than the unmodified shive. Couple with the cementing materials effect which was vividly shown in Figure 1.

The DT-TGA spectra indicates the heat behavior and state transition of the optimized sorbent. The TG thermogram

Table 3- Crude oil adsorption of Raw, Unextracted, Exracted and Optimised Styrene Grafted kenaf shive/core at $40^{\circ} \mathrm{C}$ for $5 \operatorname{mins}[14]$.

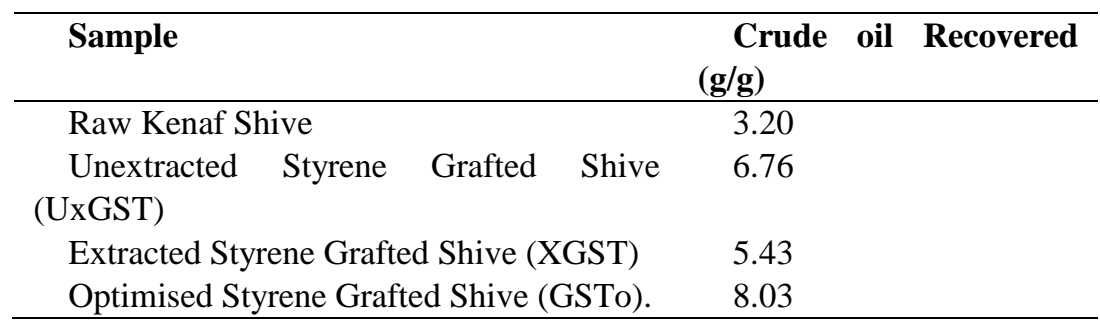

Table 4: Comparative adsorption capacities of different sorbents for crude oil

\begin{tabular}{|c|c|c|c|}
\hline Adsorbents & $\begin{array}{l}\text { Maximum Sorption } \\
(\mathrm{g} / \mathrm{g})\end{array}$ & Capacity & $\begin{array}{l}\text { Referen } \\
\text { ces }\end{array}$ \\
\hline $\begin{array}{l}\text { Crosslinked-1-Octene/styrene/DVB } \\
\text { terpolymer }\end{array}$ & 40 & & {$[25]$} \\
\hline Carbon fibre aerogel & 115 & & {$[23]$} \\
\hline Graphene coated melamine sponge & 165 & & {$[22]$} \\
\hline Silanized melamine sponge & 163 & & {$[4]$} \\
\hline Polypropylene & 15 & & {$[13,26]$} \\
\hline Banana skins & $5-7$ & & {$[3]$} \\
\hline Silanized cellulose aerogel from paper waste & 24.4 & & {$[5]$} \\
\hline Acrylic acid modified kenaf shive & 7 & & [26] \\
\hline \multirow[t]{2}{*}{ Styrene modified kenaf shive } & 8.03 & & This \\
\hline & & & work \\
\hline
\end{tabular}




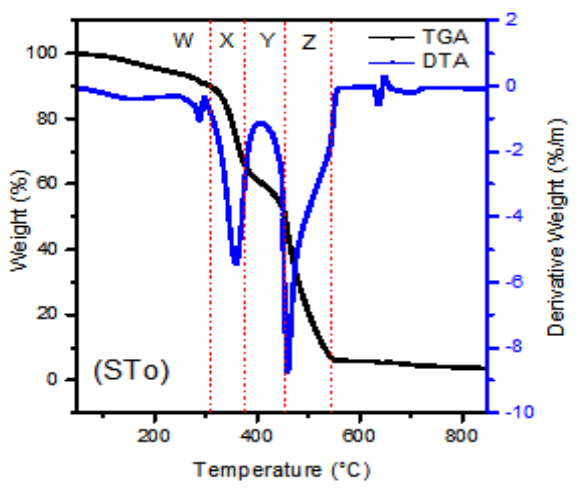

Figure 2: DTA-TGA thermogram for optimized styrene grafted shive (STo)

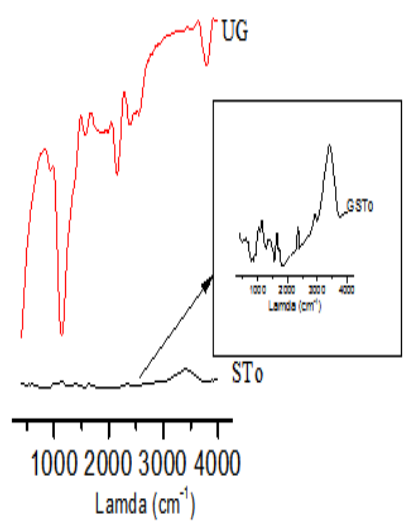

Figure 3: FTIR spectra for modified and unmodified kenaf shive

\section{Adsorption Kinetics}

Adsorption kinetics curve for the modified and optimized Kenaf Shive sorbent was exemplified in Figure 3. The relationship for the adsorption per unit time was tested in oil-water system. The slope at each point indicates the instantaneous sorption capacity. The adsorption capability increases rapidly at the initial stage i.e. $0-5 \mathrm{~min}$. A slow increase in adsorption was observed up to $30 \mathrm{~min}$, after, the curve flattens indicating equilibrium adsorption. This phenomenon was attributed to the increase in pore size of the optimized sorbent which was justified by the BET results analysis. Hence, the used oil is hydrophobic and viscose which made it slightly soluble in water, then couple with hydrophobic nature of the modifier leads to the high adsorption capability. The diffusion becomes slow when the pore sizes reduce this contributes to the slowness and little increase in sorption capacity after $30 \mathrm{~min}$.

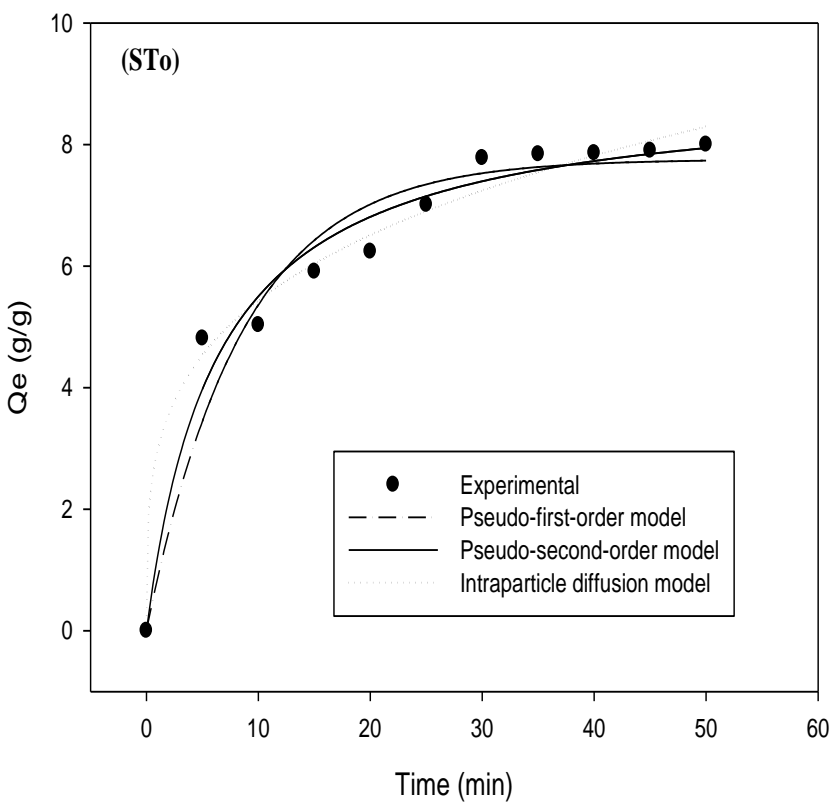

Figure 4: Kinetics of crude oil sorption on modified and optimized kenaf shive sorbent

This study shows that out of the three (pseudo-first-order, pseudo-second-order and intraparticle diffusion) kinetic models used the behavior that best fits the sorption capacity of this modified and optimized sorbent is pseudo-first-order. This was proven by correlation coefficient $\left(\mathrm{R}^{2}\right)$ of the three said models. The $\mathrm{R}^{2}$ of pseudo-first-order is 0.9502 with sorption capacity $7.82 \mathrm{~g} / \mathrm{g}$. The corresponding $\mathrm{R}^{2}$ and sorption capacities were shown in Table 5 .

Table 5: Kinetic parameters for modified/optimized kenaf shive sorption in oil/water system

\begin{tabular}{ccc}
\hline Kinetic Model & $\begin{array}{c}\text { Paramet } \\
\text { ers }\end{array}$ & $\begin{array}{c}\text { Val } \\
\text { ue }\end{array}$ \\
\hline \multirow{3}{*}{ Pseudo-first-order } & $Q_{e}$ & 7.9 \\
& $K_{1}$ & 900 \\
& $R^{2}$ & 0.0 \\
& & 142 \\
& & 0.7 \\
Pseudo-second-or & $Q_{e}$ & 453 \\
der & $K_{2}$ & 8.0 \\
& $R^{2}$ & 100 \\
& & 757 \\
Intraparticle & & 0.9 \\
diffusion & $C$ & 603 \\
& $K_{\mathrm{a}}$ & 0.0 \\
& $R^{2}$ & 581 \\
& & 5.7 \\
& & 0.8 \\
\hline
\end{tabular}




\section{Recovery of Crude Oil from Aqueous Medium by Optimised Styrene/Kenaf Shive Graft-Based Sorbent Via Regeneration Method: Study of the Equilibrium, Kinetics and Activation Energy}

\section{Adsorption Isotherm}

Sorption isotherms describe the equilibrium existence between the liquid and solid phase, however, shows the interrelation between solute and sorbent. It is therefore, important in the sorbent optimization. Besides, it also gives the capacity of the sorbent and the equilibrium relationships between sorbent and sorbate. In other words, the ratio between the quantity sorbed and the remaining in solution at fixed temperature at equilibrium. In this study the data are fitted into prominent models; Langmuir and Freundlich isotherms. These isotherm models were depicted in Figure 4.9.3 whose constant values express the affinity of sorbate to surface of sorbent.

The Langmuir Isotherm model was developed to describe a monolayer sorption onto a solid surface of specific finite number of identical binding sites. This model shows the equilibrium distribution of sorbate onto solid or liquid sorbents with the assumption of monolayer formation on homogenous energy surface [7, 15, 18]. The sorption mechanisms in this model involve three steps: the diffusion of ions residue to the external surface of sorbent; the diffusion into the pores of sorbent; and the sorption of the residue on the internal surface of sorbent [16].

Initial concentration and contact time are the basic factors that affect the first part of this model and the final part is considered as rate determining step that is relatively quick process. Linearized form of Langmuir equation was used in this studies.

The Freundlich isotherm model is applied in the intensity estimation of sorbent towards sorbate. One major characteristic of the Freundlich isotherm, though not based on a theoretical background, is its ability to give a good representation of equilibrium data over a restricted range of concentration. The model assumes that the removal of crude oil molecules occurs on a heterogeneous sorbent surface and can be applied to multilayer sorption $[3,19]$. The equilibrium data were treated with the linearized Freundlich isotherm equations.

The mathematical model for the adsorption isotherm for modified kenaf shive in an oil/water mixture at $313 \mathrm{~K}$ is presented. The results are shown in Figure 4 and Table 5. Comparison of the $\mathrm{R}^{2}$ values (Table 5) reveals that the Langmuir model is the best fitting to explain the adsorption of crude oil from the optimized kenaf shive sorbent(GSTo).

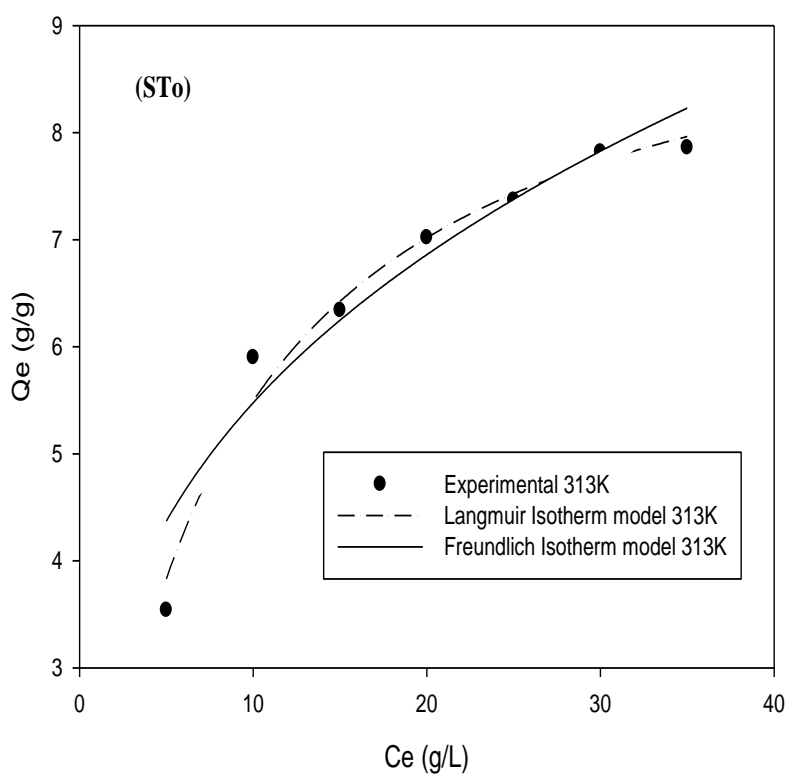

Figure 5: Isotherm of crude oil sorption on modified and optimized kenaf shive sorbent (STo)

Table 6: Thermodynamic parameters for the sorption of crude oil onto optimized kenaf shive sorbent

\begin{tabular}{ccc}
\hline $\begin{array}{c}\text { Isotherm } \\
\text { Model }\end{array}$ & $\begin{array}{c}\text { Isotherm } \\
\text { Constants }\end{array}$ & $\begin{array}{c}\text { Temperature } \\
(313 \mathrm{~K})\end{array}$ \\
\hline Langmuir & $Q_{0}$ & 10.4743 \\
& $K_{1}$ & 0.0804 \\
& $R^{2}$ & 0.9003 \\
Freundlich & $n$ & 0.4812 \\
& $K_{2}$ & 0.1943 \\
& $R^{2}$ & 0.8224 \\
\hline
\end{tabular}

\subsection{Thermodynamic Studies}

The thermodynamic parameters, values $\Delta \mathrm{G}$ and $\Delta \mathrm{H}$ can be calculated by plotting $\ln (\mathrm{Qe} / \mathrm{Ce}$ ) versus $1 / \mathrm{T}$ (Figure 4.9 .4 and Table 4.9.2). The $\Delta \mathrm{G}$ values of the developed sorbent ranges between approximately -20 to $82 \mathrm{~kJ} / \mathrm{mol}$ at temperatures of $303,313,323,333 \mathrm{~K}$, indicates that in the adsorption process, crude oil molecules are spontaneously adsorbed from the mixture of the oil/water to surface of modified sorbents. This appeared for the sorbents having a negative $\Delta \mathrm{Gs}$, however, for those sorbents having positive $\Delta \mathrm{G}$ appeared to be nonspontaneous. It also observed that as the temperature increases $\Delta \mathrm{G}$ reduces, in other words is inversely related with temperature. Consequently, higher temperatures leads to weaker driving force of adsorption, in addition, lead to more difficult sorption of the oil $[2,7,15]$. If $\Delta S<0$, then the oil molecules movement in the developed sorbent is said to be limited and show a level of orderliness as well as decrease in randomness at the solid-mixture interface during the adsorption of crude oil from water due to the highly ordered crude oil molecules in the hydrophobic layer of the sorbents at adsorption equilibrium. 


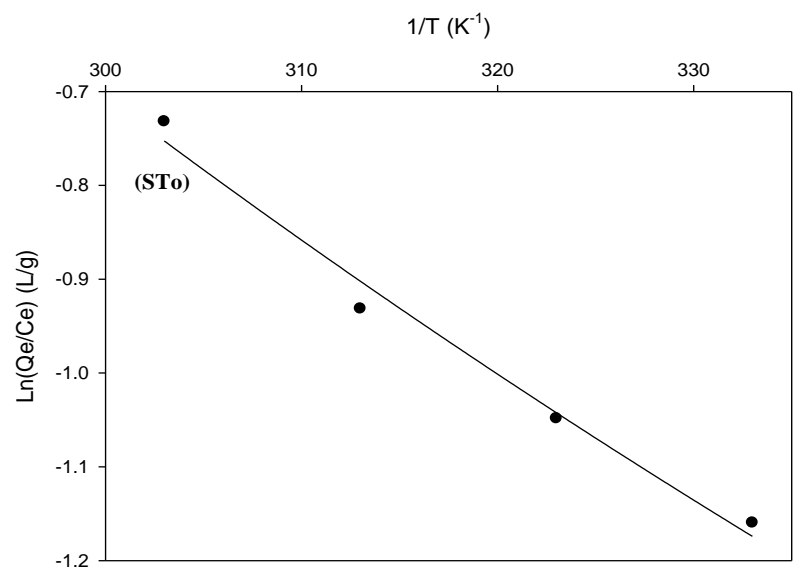

Figure 6: Plot of $\ln \left(Q_{e} / C_{e}\right)$ against $\frac{1}{T}$ for crude oil adsorption of optimized kenaf shive sorbent for thermodynamics parameters

Table 7: thermodynamics parameters for crude oil sorption on optimized kenaf shive sorbent

\begin{tabular}{|c|c|c|c|c|c|}
\hline $\begin{array}{r}\mathbf{T} \\
(\mathbf{K})\end{array}$ & $\begin{array}{c}\Delta G \\
\left(\mathbf{k J} . \mathrm{mol}^{-1}\right)\end{array}$ & $\begin{array}{c}\Delta \mathbf{H} \\
\left(\mathbf{k J} . \mathrm{mol}^{-1}\right)\end{array}$ & $\begin{array}{c}\Delta S \\
\left(\text { J.mol }^{-1} \cdot \mathbf{K}^{-1}\right)\end{array}$ & $\begin{array}{c}\text { Ea } \\
\left(\mathbf{k J} . \mathrm{mol}^{-1}\right)\end{array}$ & $R^{2}$ \\
\hline 303 & 49.04 & & & & \\
\hline 313 & 49.49 & -35.36 & 45.16 & 25.64 & 0.9847 \\
\hline 323 & 49.94 & & & & \\
\hline 333 & 50.40 & & & & \\
\hline
\end{tabular}

\subsection{Activation Energy}

Activation energy, Ea is an important thermodynamic parameter which must be overcome by a sorbate before sorption interaction occur with the functional groups of the sorbent surface.

The activation energy can be determined from the change of the absorption rate constant, $\mathrm{k}$ with temperature, $\mathrm{T}(\mathrm{K})$ using the Arrhenius equation [7, 18]:

$$
\ln K=\ln A-\frac{E_{a}}{R T}
$$

Where $\mathrm{A}$ is the pre-exponential factor and $\mathrm{R}$ is the gas constant $(8.314 \mathrm{~J} / \mathrm{mol} \mathrm{K})$. By plotting $\ln \left[\mathrm{k}_{2}\right]$ against $1 / \mathrm{T}, E_{a}$ and $\ln A$ can be calculated respectively, from the slope and intercept. The pseudo-second-order constant was used in the activation energy manipulation because the kinetic equation that best fitted the kinetic models is the second-order.

In this studies, the best kinetic model of each sorbent was used at different temperatures of 303, 313, 323 and $333 \mathrm{~K}$. The natural logarithms of the absorption rate constants, $\mathrm{k}_{1}$ was plotted against the $1 / \mathrm{T}$. In a nut shell, the sorbents that were best fitted with say, Pseudofirst- order, the rate constant $\mathrm{k}$, was determine at four different temperatures. However, such rates were plotted against the corresponding $1 / \mathrm{T}$.

Plots of lnk versus 1/T are presented in (Figure 6), the activation energy value is presented in Table 7 .

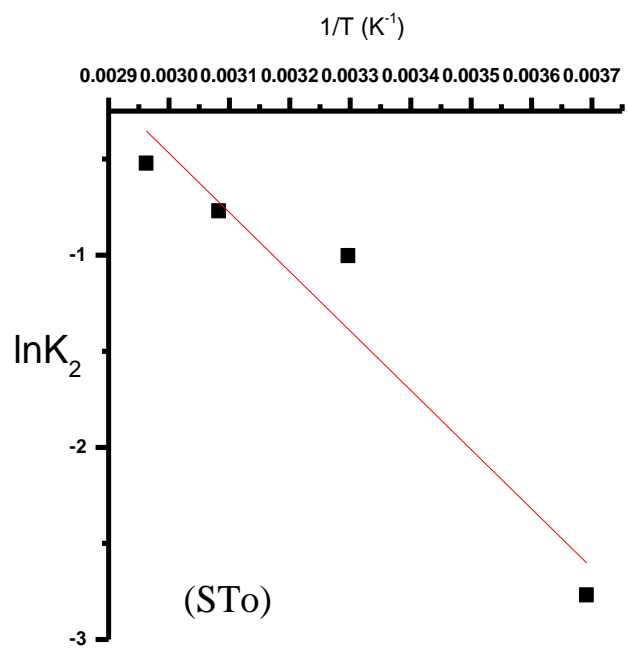

Figure 7: Plot of $\ln k_{2}$ against $\frac{1}{\pi}$ for crude oil adsorption of optimized kenaf shive sorbent for activation energy parameters

Generally speaking, the developed sorbent has lower activation energy because is between $5-50 \mathrm{~kJ} / \mathrm{mol}$ [7, 17-20]. Pseudosecond-order model has higher than those of the pseudo first-order model. This is because the corresponding models used for the absorption process controlled by chemisorption, which involves higher forces than in physic-sorption. Moreover, the physisorption phenomenon that was observed by the sorbents/mixture interface is an isosteric heat behavior of its enthalpy $(\Delta \mathrm{H})[13]$. 


\section{Recovery of Crude Oil from Aqueous Medium by Optimised Styrene/Kenaf Shive Graft-Based Sorbent Via Regeneration Method: Study of the Equilibrium, Kinetics and Activation Energy}

\section{CONCLUSION}

The imparting hydrophobic property on to kenaf shive was achieved and effective via regeneration (grafting) method. The merit of using this cellulosic material (kenaf shive) is due to its low economic importance and high abundancy moreover, withstanstand different climatic changes. Combating this menace using the kenaf shive added value as it is the $60-70 \%$ of the plant. The variables (particle sizes, initiator and monomer concentration) which have important role in the modification of this facile sorbent were studied. Comparing the developed eco-friendly sorbent with natural based sorbent shows a remarkable sorption capability of $8.0 \pm 0.02 \mathrm{~g} / \mathrm{g}$. The basis for this facility is supported by structural analysis. FTIR support the achievement for the modification. BET, DT-TGA and XRD elucidate in the surface structure of the optimized sorbent consequently, increase the crude oil uptake from water/oil mixture. The kinetic model exhibited by the regenerated kenaf shive developed is pseuosecond-order model. The sorption is controlled by film ${ }^{-}$diffusion via internal diffusion transport mechanism. Comparing the Freundlich sorption isotherm, the Langmuir equation best fitted the sorption process of crude oil onto optimized regenerated kenaf shive sorbent. The experimental data obtained from thermodynamic parameters in this study validate the spontaneity and exothermic phenomenon of the crude oil sorption. The low activation energy indicates physisorptionphenomenon.

\section{REFERENCES}

[1] Romero, I.C.; Toro-Farmer, G.; Diercks, A.R.; Schwing, P.; Muller-Karger, F.; Murawski, S.; Hollander, D.J. 2017. Large-scale deposition of weathered oil in the Gulf of Mexico following a deep-water oil spill. Environ. Pollut. 2017, 228, 179-189

[2] Nwadiogbu, J.O.; Ajiwe, V.I.E.; Okoye, P.A.C. 2016.Removal of crude oil from aqueous medium by sorption on hydrophobic corncobs: Equilibrium and kinetic studies. Journal of Taibah University for Science 10 (2016) 56-63.

[3] Bhairavi D.; Mika S.; Simo K. 2018. A review of bio-based materials for oil spill treatment. Journal of Water Research 135 (2018) 262-277.

[4] Viet, H. P and James, H. D; 2014, "Superhydrophobic Silanized Melamine Sponges as High Efficiency Oil Absorbent Materials". American Journal of Science and Industrial Research, dx.doi.org/10.1021/am503503m| ACS Appl. Mater. Interfaces2014, 6, 14181-14188.

[5] Singh, V.; Kendall, R. J.; Hake, K.; Ramkumar, S.; 2014 "Crude Oil Sorption by Raw Cotton" Ind. Eng. Chem. Res. 2013, 52, 6277.

[6] Son, T. Nguyen; Jingduo, Feng; Nhat, T. Le Ai; T. T. Le; Nguyen, Hoang; Vincent, B. C. Tan; Hai, M. Duong; 2013, "Cellulose Aerogel from Paper Waste for Crude Oil Spill Cleaning". Industrial and Engineering Research,dx.doi.org/10.1021/ie4032567

[7] Na, L.; Xiaoli, W., Shitao, P.; Huaqin, Z.; Lei, L. 2018. Study of the kinetics and equilibrium of the adsorption of oils onto hydrophobic jute fiber modified via the sol-gel method. International journal of environmental research and public health.

[8] Yuan, X.; Chung, T. C. M. 2012 "Novel Solution to Oil Spill Recovery: Using Thermodegradable Polyolefin Oil Superabsorbent Polymer (Oil-SAP)”. Energy Fuels 2012, 26, 4896.

[9] Nur Azmyra A., Aznizam A., Azman H., Nurulhusna A., (2014). Synthesis of chitosan-grafted-poly(methyl methacrylate) with fenton's reagent $\left(\mathrm{Fe}^{2+}-\mathrm{H}_{2} \mathrm{O}_{2}\right)$ as a redox initiator.Malaysian Journal of Analytical Sciences, Vol 18 No 2 (2014): 415 - 422

[10] EPA, 2017. Oil Spill Response Techniques, EPA's Response Techniques [Online]Available https://www.epa.gov/emergency-response/epas-responsetechniques
[11] Itodo, A.U.; Happiness, U.O.; Obaroh, I.O.; Usman, A.; Audu, S. S. 2009. Temkin, R-D, Langmuir and Freundlich sorption Isotherms of industrial dye uptake unto $\mathrm{H} 3 \mathrm{PO} 4$ catalyzed poultry waste biosorbent, J. Sci. Technol. Res., vol. 8, no. 1, pp. 52-56.

[12] Sajab, M.S.; Chia, C.H.; Zakaria, S.; Jani, S.M.; Ayob, M.K.; Chee, K.L; Khiew, P.S.; Chiu, W.S. 2011. Citric acid modified kenaf core fibres for removal of methylene blue from aqueous solution. $\begin{array}{llll}\text { Bioresource } & \text { Technology } & 102 & \text {,7237-7243. }\end{array}$ www.elsevier.com/locate/biortech.

[13] Sidik, S.M., Jalil, A.A., Triwahyono, S., Adam, S.H., Satar, M.A.H., Hameed, B.H. 2016. Modified oil palm leaves adsorbent with enhanced hydrophobicity for crude oil removal. Chemical Engineering Journal. www.elsevier.com/locate/cej

[14] Salisu, Z.; Isiaku, US.; Abdullahi, D.; Yakubu, MK.; Diya'uddeen, BH. 2019a. Optimisation of crude oil adsorbent developed from a modified styrene kenaf shive. Journal of Scientific Research pp. 34-47.

[15] Nethaji, S.; Sivasamy, A.; Mandal, AB. 2013. Adsorption isotherms, kinetics and mechanism for the adsorption of cationic and anionic dyes onto carbonaceous particles prepared from Juglans regiashell biomass. Int. J. Environ. Sci. Technol. (2013) 10:231-242.DOI 10.1007/s13762-012-0112-0

[16] Nasehir Khan E M Y.; Muhamad FP ML.; Ismail, A.; Olugbenga, SB.; Mohd, AA. 2011.Adsorptive Removal of $\mathrm{Cu}$ (II) Using Activated Carbon Prepared From Rice Husk by $\mathrm{ZnCl} 2$ Activation and Subsequent Gasification with $\mathrm{CO}$. International Journal of Engineering \& Technology IJET -IJENS Vol: 11 No: 01

[17] Yin, T.; Zhang, X.; Liu, X.; Wang, C. 2017. Resource recovery of eichhornia crassipes, as oil superabsorbent. Mar. Pollut. Bull. 2017, 267-274.

[18] Wang, Z.; Ma, H.; Chu, B.; Hsiao, B.S. 2017. Super-hydrophobic modification of porous natural polymer "luffasponge" for oil absorption. Polymer 2017, 126, 470-476.

[19] Ju, H.L.; Kim, D.H.; Sang, W.H.; Bo, R.K.; Park, E.J.; Jeong, M.G.; Kim, J.H.; Kim, Y.D. 2016 Fabrication ofsuperhydrophobic fibre and its application to selective oil spill removal. Chem. Eng. J. 2016, 289, $1-6$.

[20] Kollarigowda, R.H., Abraham, S., Montemagno, C.D., 2017. Antifouling cellulosehybrid biomembrane for effective oil/water separation. ACS Appl. Mater. Interfaces 9, 29812-29819.

[21] Li, J., et al., 2016. A prewetting induced underwater superoleophobic or underoil(super) hydrophobic waste potato residue-coated mesh for selective efficientoil/water separation. Green Chem. 18, 541-549.

[22] [22] Feng, Y., Liu, S., Liu, G., Yao, J., 2017. Facile and fast removal of oil through porouscarbon spheres derived from the fruit of Liquidambar formosana. Chemosphere 170, 68-74.

[23] [23] Liu, H., Geng, B., Chen, Y., Wang, H., 2017. Review on the aerogel-type oil sorbentsderived from nanocellulose. ACS Sutainable Chem. Eng. 5, 49-66

[24] Cheng, Q., Ye, D., Chang, C., Zhang, L., 2017. Facile fabrication of superhydrophilicmembranes consisted offibrous tunicate cellulose nanocrystals for highlyefficient oi/water separation. J. Membr. Sci. $525,1-8$

[25] Ajay, K.; Amit, K.; Gaurav, S.; Ala'a, H.; Al-M, M.N.; Ayman, A.G.; Florian, $\quad$ J.S. $2018 . \quad$ Quaternarymagnetic $\mathrm{BiOCl} / \mathrm{g}-\mathrm{C}_{3} \mathrm{~N}_{4} / \mathrm{Cu}_{2} \mathrm{O} / \mathrm{Fe}_{3} \mathrm{O}_{4}$ nano-junction for visible light and solar powered degradationof sulfamethoxazole from aqueous environment. Chem. Eng. J. 2018, 334, 462-478

[26] Salisu, Z.; Isiaku, US.; Danladi, A.; Yakubu, MK.; Diya'uddeen, BH 2019b. Facile fabrication and optimisation of kenaf shive aerogel via regeneration method. Unpublished paper. 